\title{
ANÁLISE DA MICROESTRUTURA E DAS PROPRIEDADES MECÂNICAS DO VERGALHÃO CA-50 EM DIFERENTES ESTADOS DE TRATAMENTO TÉRMICO*
}

Ana Larissa Melo Feitosa ${ }^{1}$ Emmanuel de Sousa Almeida ${ }^{1}$ Giovani Gonçalves Ribamar ${ }^{2}$ Marcelo José Gomes da Silva ${ }^{3}$

\section{Resumo}

Devido ao crescimento acelerado da construção civil e ao alto consumo de produtos metálicos nessa área, cada vez mais procuram-se, nesses materiais, propriedades que se adequem às diversas necessidades do mercado. O conhecimento microestrutural desses materiais, bem como a manipulação da microestrutura pela utilização dos tratamentos térmicos, é de extrema importância para garantir a segurança no desenvolvimento de novas construções. Para analisar e entender as mudanças que os tratamentos térmicos podem oferecer, utilizou-se como material de pesquisa, vergalhões da classe CA-50, visto que esse é o mais comum no mercado nacional atual, e realizouse o estudo de suas propriedades e de sua microestrutura em três estados distintos: como recebido, temperado em água e recozido ao forno. As propriedades e características dos três estados foram comparadas e analisadas por meio de microscopia óptica, microscopia eletrônica de varredura, ensaios de tração e microdureza, objetivando-se compreender a relação entre as alterações microestruturais promovidas pelo processo de tratamento térmico e as propriedades mecânicas resultantes. A análise por microscopia óptica foi utilizada com o objetivo de se determinar constituintes e fases presentes nos diferentes estados. A análise por microscopia eletrônica teve como ênfase o estudo da fratura após o ensaio de tração. Os resultados encontrados ficaram em concordância com os esperados, em termos de propriedades e microestrutura.

Palavras-chave: Construção civil; Tratamentos Térmicos; Propriedades Mecânicas; Microestrutura.

\section{MICROSTRUCTURAL AND MECHANICAL ANALYSIS OF CA-50 REBARS IN DIFFERENT HEAT TREATMENT STATES}

\begin{abstract}
Due the fast growth of civil construction and the high consumption of metal products in this area, more and more are sought in these materials, properties that meet the diverse needs of market. The microstructural knowledge of these materials and your microstructural manipulation by use of heat treatment, it is extremely important to ensure safety in the development of new buildings. To analyze and understand the changes that heat treatments can offer, was used as research material, CA-50 rebars, as this is the most common in the current national market, and the study of their properties was conducted and its microstructure in three different states: as received, quenched in water and annealed in the oven. The properties and characteristics of the three states were compared and analyzed using optical microscopy, scanning electron microscopy, tensile and hardness tests, aiming to understand the relationship between the microstructural changes introduced by heat treatment process and the resultant mechanical properties. Analysis by optical microscopy was used with the objective of determining phases and constituents present in different states. The analysis by electron microscopy was to emphasis the study of fracture after the tensile test. The results were in agreement with those expected in terms of properties and microstructure than there are on literature.

Keywords: Construction; Heat treatments; Mechanical properties; Microstructure.

1 Graduação em Engenharia Metalúrgica, graduanda, Departamento de Engenharia Metalúrgica e de Materiais, Universidade Federal do Ceará (UFC), Fortaleza, Ceará, Brasil.

2 Pós-graduação Eng. e Ciência de Materiais, mestrando, Depto. Eng. Met. e Mat., UFC, Fortaleza, CE, Brasil.

3 Eng. Nuclear, Doutor, professor, Depto. Eng. Metalúrgica e de Materiais, UFC, Caucaia, CE, Brasil.
\end{abstract}




\section{INTRODUÇÃO}

\subsection{Importância dos vergalhões na construção civil}

A introdução de barras de aço para concreto armado, ou simplesmente vergalhões, na indústria da construção civil, é realizada há muitos anos e é de extrema importância para garantir a resistência mecânica das estruturas de concreto. O uso combinado do vergalhão, que garante boa resistência à tração e boa ductilidade, e do concreto, que garante excelente resistência à compressão, é responsável pelo desenvolvimento de grandes construções e soluções de engenharia na construção civil. (DAROIT, 2012, p.15). Os vergalhões utilizados nesta pesquisa são de aço microligado ao vanádio e possuem com elementos de liga principais: $0,125 \%$ de vanádio, $1,327 \%$ de manganês e $0,136 \%$ de cobre.

\subsection{Tratamentos Térmicos}

Tratamentos térmicos são utilizados para controlar as diversas fases que podem se formar na microestrutura do aço, bem como definir a morfologia e o tamanho de grão. Os tratamentos térmicos em aços possibilitam a formação de microconstituintes conhecidos como ferrita, bainita, martensita e austenita, em que a composição entre os diferentes microconstituintes torna-se fator decisivo, juntamente com sua morfologia, para as propriedades mecânicas finais do material e pode ser programada em conformidade com as exigências de projeto. Dos tratamentos térmicos existentes, os mais comumente utilizados são: têmpera e recozimento. (ANAZAWA; ABDALLA, 2012, p.2).

A têmpera é um tratamento térmico de aços com a finalidade de aumentar a dureza e a resistência dos mesmos. Esse processo consiste do aquecimento do material, promovendo sua austenitização, e do resfriamento brusco, provocando uma transformação adifusional no aço, mais conhecida como transformação martensítica. Essa transformação é caracterizada pelo cisalhamento da rede cristalina, e mudança na morfologia da microestrutura, podendo ter formação de agulhas ou placas. No tocante às propriedades mecânicas, essa fase tem característica de aumentar a dureza e diminuir a tenacidade, resultado do acúmulo de tensões na rede cristalina. O recozimento consiste no tratamento térmico mais importante dos aços, principalmente os que são utilizados em construção mecânica. Tem-se duas etapas do processo: aquecimento e resfriamento lento. $O$ aquecimento também terá como objetivo chave a obtenção de uma estrutura austenítica, já o resfriamento lento, ao forno, permitirá uma maior difusão por todo o material, possibilitando, assim, a formação de uma estrutura de perlita grosseira, com menor área de contorno de fase e de grão, possibilitando um ganho em tenacidade e ductilidade à estrutura formada.

\subsection{Processo Stelmor®}

Os vergalhões utilizados na pesquisa passaram pelo processor conhecido como Stelmor®. O sistema de resfriamento Stelmor® compõe-se basicamente de dois estágios: no primeiro, o fio máquina é bruscamente resfriado ao passar em duas ou mais zonas de resfriamento a água equipadas com bicos de pulverização com elevada pressão e vazão. Entre estas zonas, existe um espaço adequado para promover a equalização da temperatura entre a superfície e o núcleo do fio máquina. Nesta etapa do processo, o objetivo é reduzir a temperatura rapidamente para aproximadamente 
$900^{\circ} \mathrm{C}$, de tal forma que se evite crescimento exagerado do grão, assim como o controle na formação de óxidos superficiais. No segundo estágio, o fio máquina tem seu resfriamento controlado através de ventilação, onde pode ser variada a taxa de resfriamento (FERREIRA, 2015, p.61).

\subsection{Propriedades mecânicas}

As propriedades mecânicas dos materiais em geral, podem ser estudadas por vários métodos. Porém, no estudo dos aços, é muito comum a utilização de ensaios de tração e dureza, pois a partir deles podem ser analisadas diversas propriedades, por exemplo, no ensaio de tração é possível verificar características como ductilidade, tenacidade, resiliência, plasticidade.

Tão importante quanto a comparação dos resultados obtidos com a teoria, é a compreensão dos fenômenos metalúrgicos presentes durante o processo, que variam de situação para situação. A motivação deste trabalho é buscar compreender, através de caracterização microestrutural, mecânica e correlação com dados da literatura, a relação que há entre o tratamento térmico aplicado e a microestrutura formada.

\section{MATERIAIS E MÉTODOS}

\subsection{Tratamentos térmicos}

Foram utilizados vergalhões CA-50 de $8 \mathrm{~mm}$ de diâmetro, fabricados pela empresa USIBA - Grupo Gerdau, os quais são encontrados no mercado como GG-50. Os vergalhões foram cortados em máquina de policorte com disco de óxido de alumínio, obtendo-se 3 peças tipo A (para ensaio de tração e estudo da fratura) e 3 peças tipo B (para metalografia e microdureza). Das peças obtidas, duas de cada tipo foram tratadas termicamente, a $900^{\circ} \mathrm{C}$, em que uma foi temperada e outra, recozida. Ao final do processo, cada grupo de amostras apresentou uma peça temperada, uma recozida e uma no estado de "como recebida". As dimensões para cada grupo foram as seguintes:

Tabela 1. Divisão das peças

$\begin{array}{lll} & \text { Tipo A }(\mathrm{mm}) & \text { Tipo B }(\mathrm{mm}) \\ \text { Altura } & 130 & 8\end{array}$

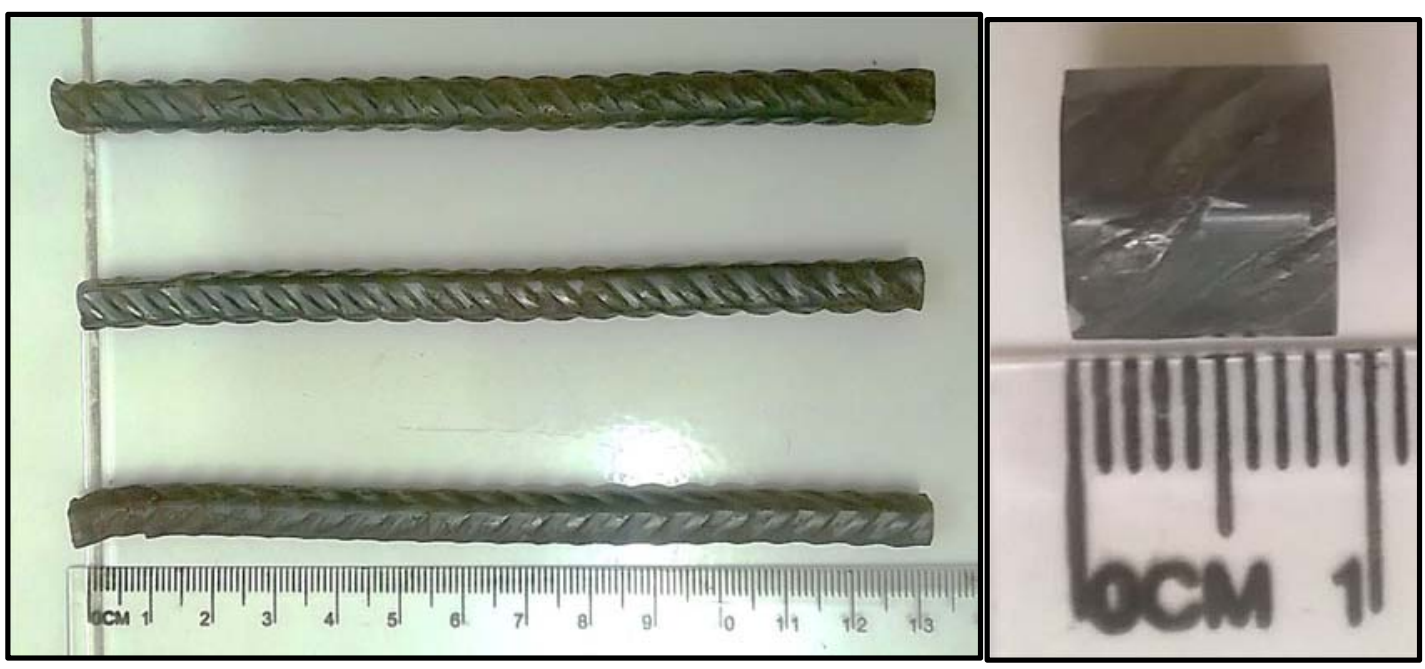

Figura 1 - Amostras cortadas a) para tração e b) para metalografia 


\subsection{Metalografia e microdureza}

As amostras do tipo B foram embutidas e lixadas com lixas de carbeto de silício, seguindo a granulação de 100, 220, 320, 400 e 600. Em seguida, polidas com pasta de diamante de granulometria de $3 \mu$ e $1 \mu$. As três amostras foram atacadas quimicamente com reagente Nital 2\% (49 mL Álcool Etílico + $1 \mathrm{~mL}$ Ácido Nítrico). Ao fim da preparação as amostras foram observadas em Microscópio óptico da marca Zeiss, operando com software AxioVisio. Para quantificação da quantidade de carbono presente no material, optou-se por utilizar o material no estado como recebido e atacá-lo com Picral 4\%, para que os contornos não interferissem na análise, assim, as imagens foram analizadas e quantificadas no software ImageJ. Para medição da microdureza, utilizou-se microdurômetro Vickers da marca Shimadzu, onde as amostras foram ensaiadas com carga de $980,7 \mathrm{mN}$ por 15 segundos. Em cada uma foram feitas 13 impressões com distância de $0,2 \mathrm{~mm}$ entre cada uma, no sentido centro-borda, o perfil de dureza foi plotado num gráfico para posterior comparação. $O$ ensaio de microdureza foi realizado de acordo com a norma que o regulamenta (ASTM E384, 2008).

\subsection{Ensaio de tração e análise de fratura}

Para os ensaio de tração utilizou-se a máquina universal de ensaios mecânicos, EMIC. As amostras do tipo A foram tracionadas a velocidade de $2 \mathrm{~mm} / \mathrm{s}$ à temperatura ambiente. Com os dados obtidos foram produzidos os gráficos Tensão x Deformação. Os ensaios seguiram requisitos da norma internacional que os regulamenta (ASTM E8/E8M, 2015). Posteriormente, as amostras fraturadas foram levadas ao microscópio eletrônico de varredura, da marca Philips XL, para análise da superfície fraturada. Com base no gráfico de resistência mecânica dos materiais, suas tenacidades (em $\mathrm{MJ} / \mathrm{m}^{3}$ ) foram estimadas pelo cálculo da área sob o gráfico. Foi utilizado o método dos retângulos para o cálculo da área.

\section{RESULTADOS E DISCUSSÃO}

\subsection{Micrografias ópticas}

As figuras 2-5 apresentam as micrografias obtidas das amostras do tipo B.
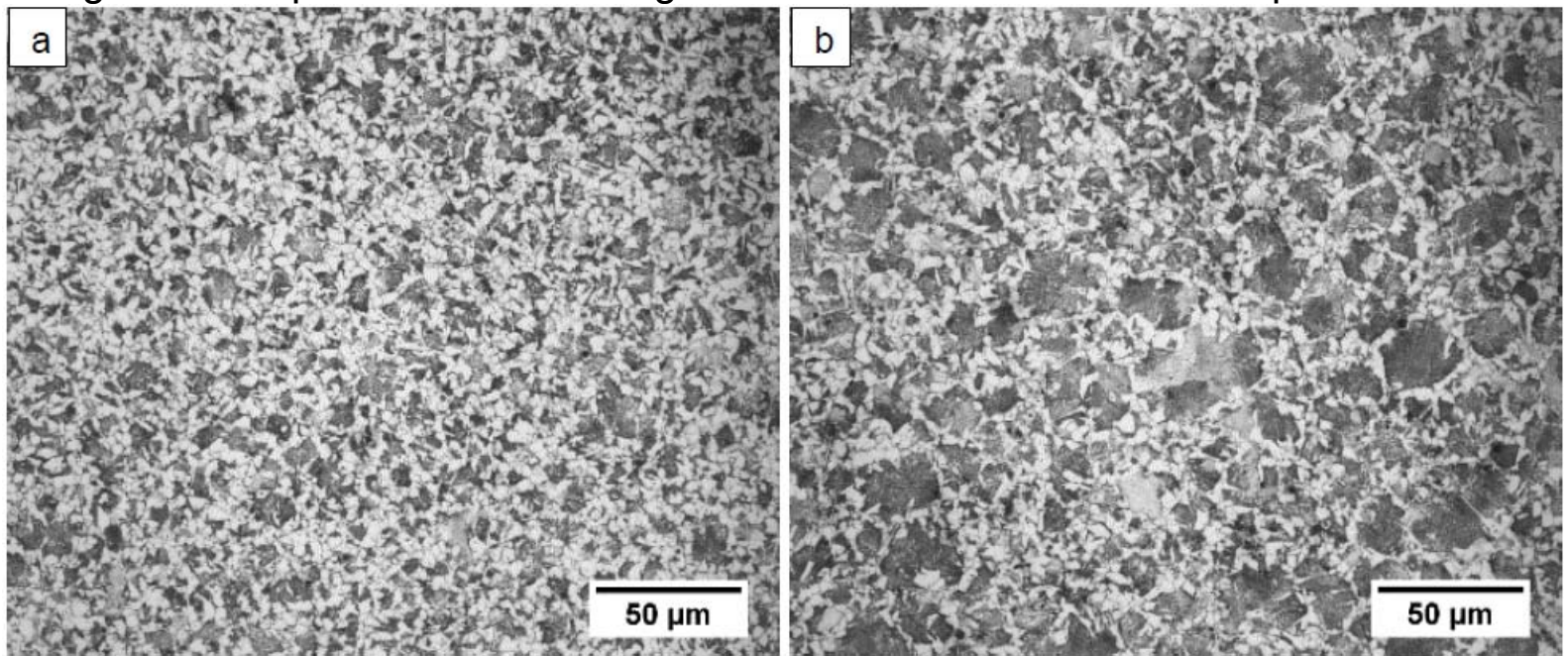

Figura 2. Vergalhão CA-50 no estado como recebido apresentando as regiões a) da borda, e b) do centro. 

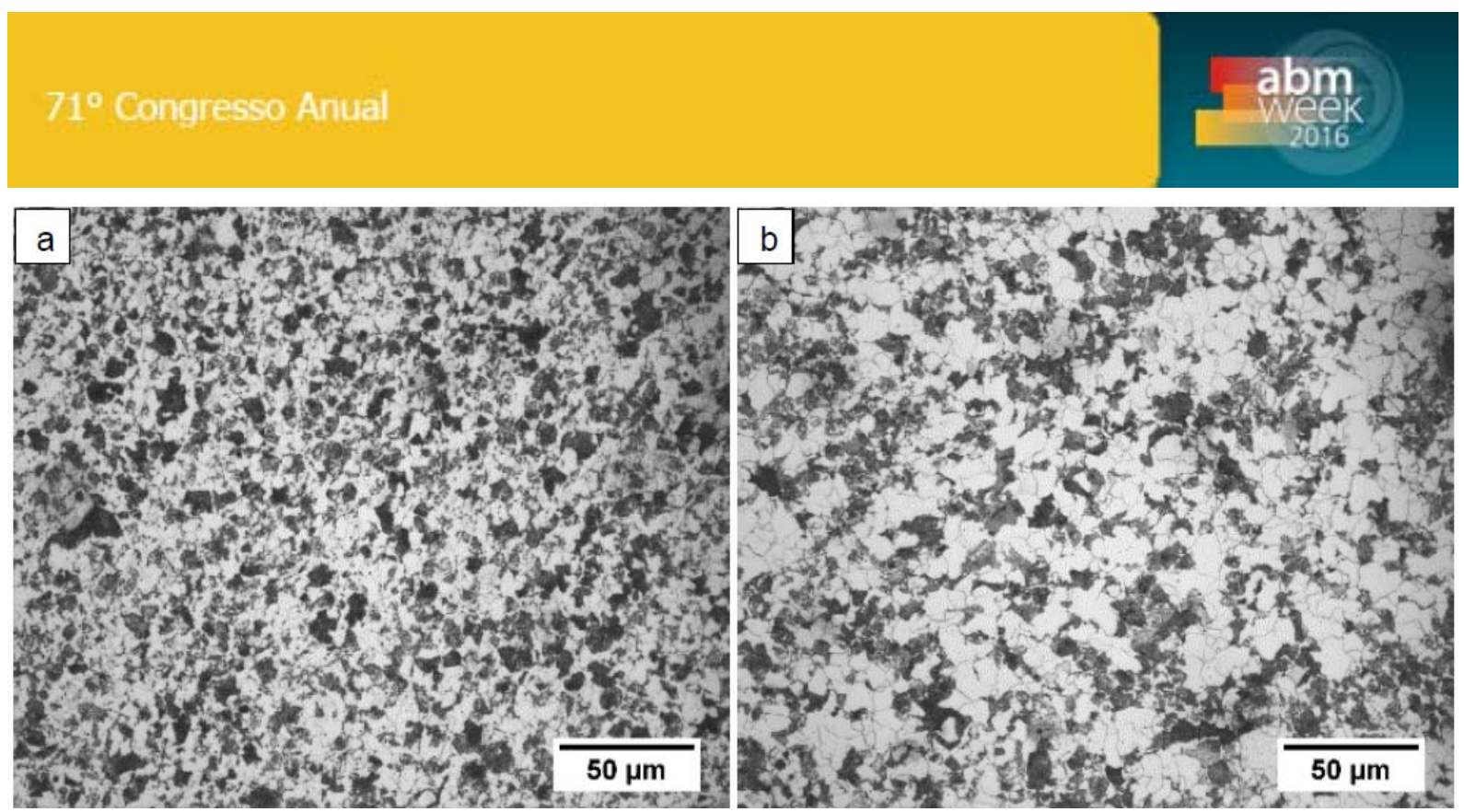

Figura 3. Vergalhão CA-50 no estado recozido, apresentando as regiões a) da borda e b) do centro.

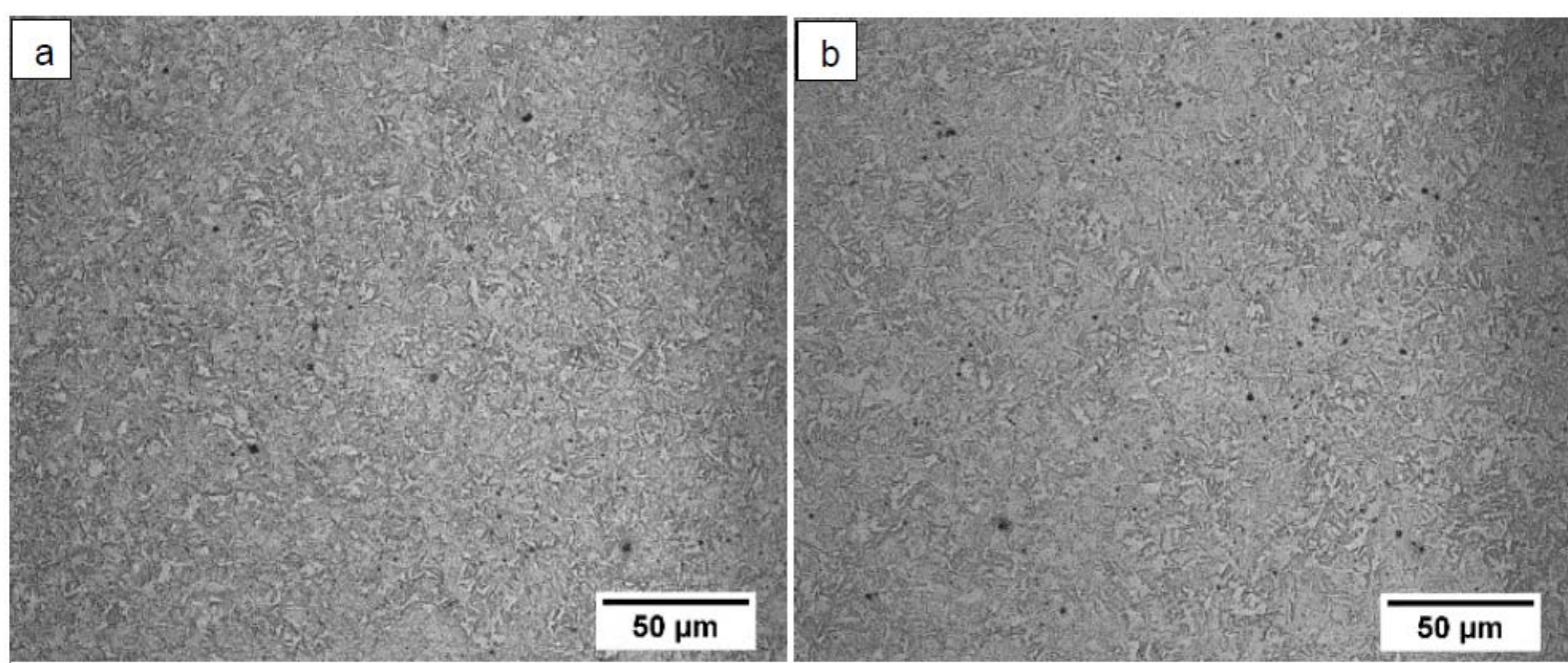

Figura 4. Vergalhão CA-50 temperado em água, apresentando as regiões a) da borda, e b) do centro.
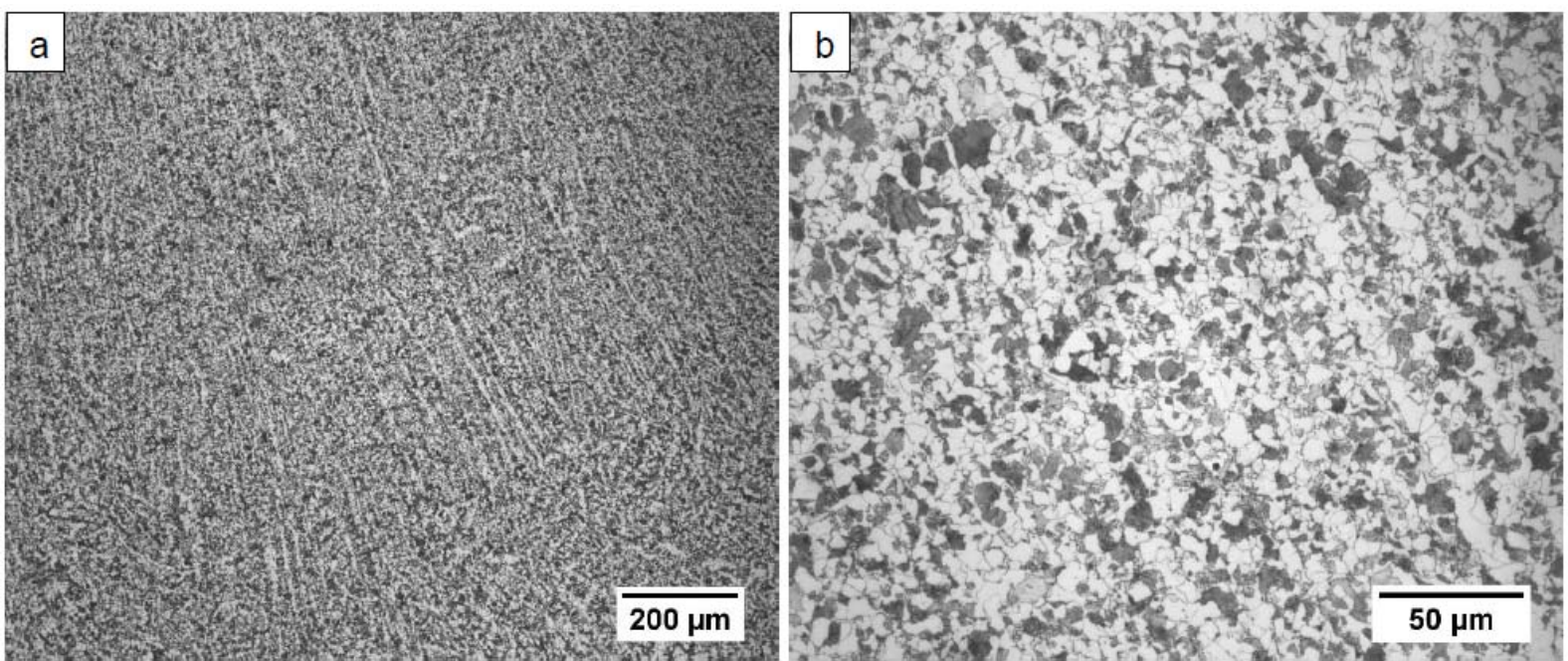

Figura 5. Vergalhão CA-50 recozido, região intermediária entre borda e centro com a) 100x e b) 500x de aumento.

Nas micrografias do estado como recebido (figura 2), nota-se a presença de grãos pequenos e equiaxiais, em que os mais escuros são constituídos de lamelas finas de ferrita e cementita, enquanto que os claros são da fase ferrita. Além disso, observa- 
se granulação mais fina na região da borda (figura 2a) do que no centro (figura $2 b$ ), esse fenômeno pode ser explicado pelo processo Stelmor, que resfria o exterior da peça de maneira mais acelerada que o núcleo. Este fenômeno não ocorre para toda a secção do material devido a sua temperabilidade, que é insuficiente para a formação de granulação mais fina também no centro da peça.

A amostra recozida apresentou estrutura com granulação mais grosseira (figura 3) que o estado como recebido, pois o resfriamento ao forno proporciona um tempo maior para que ocorra difusão, favorecendo o aumento dos grãos. O estado recozido também apresentou estrutura mais refinada na borda e mais grosseira no centro, pois há uma relação com a estrutura anterior do vergalhão (estado como recebido). Provavelmente o tempo de austenitização de 16 minutos não foi suficiente para igualar o tamanho dos grãos da borda com os do centro.

Observa-se maior presença de ferrita pró-eutetóide na amostra recozida, isso pode ser explicado pelo fato de menores taxas de resfriamento favorecerem a formação dessa fase nos aços hipoeutetóides, pois há mais tempo para que ocorra a difusão. O estado temperado apresentou estrutura completamente diferente dos outros (figura 4), apresentando estrutura única e uniforme de morfologia semelhante à martensita, visto que a estrutura possui placas ao longo de toda sua extensão, indicando cisalhamento da rede. Observa-se também que não há mudanças nas estruturas da borda e do centro. A estrutura também apresenta pontos escuros, os quais possivelmente se tratam de pites gerados pelo ataque químico, ou de arranchamento de material devido a preparação metalográfica.

O estado recozido também apresentou uma estrutura de morfologia diferente entre os grãos finos da borda e os grãos grosseiros do centro, apresentando grãos de ferrita alinhados na direção radial do material. Na figura 5a é possível observar linhas mais claras na estrutura, onde é possível identificar, pela figura $5 \mathrm{~b}$, o alinhamento dos grãos de ferrita. É importante salientar que os grãos não são colunares, mas equiaxiais, e seu alinhamento na direção radial apresenta forma colunar. Esse fenômeno ainda não foi entendido pelos autores, sendo uma evidência para posterior estudo.

\subsection{Quantificação de carbono}

Utilizando-se o software ImageJ, foi possível estimar a quantidade de carbono que o vergalhão apresenta, e como foi possível perceber pelo GG50 fabricado pela Gerdau não apresentou o percentual que normalmente é proposto na literatura de $0,26 \% \mathrm{C}$, mas uma variação entre $0,36 \% \mathrm{C}$ na borda e $0,42 \% \mathrm{C}$ no centro (PEREIRA, 2009). Isso pode explicar melhor o fato do material ter temperado sem grandes dificuldades, pois maiores teores de carbono melhoram a temperabilidade dos aços carbono, tornando mais fácil a formação da martensita em grande profundidade, quando resfriados rapidamente. 


\subsection{Microdureza}

\section{4}

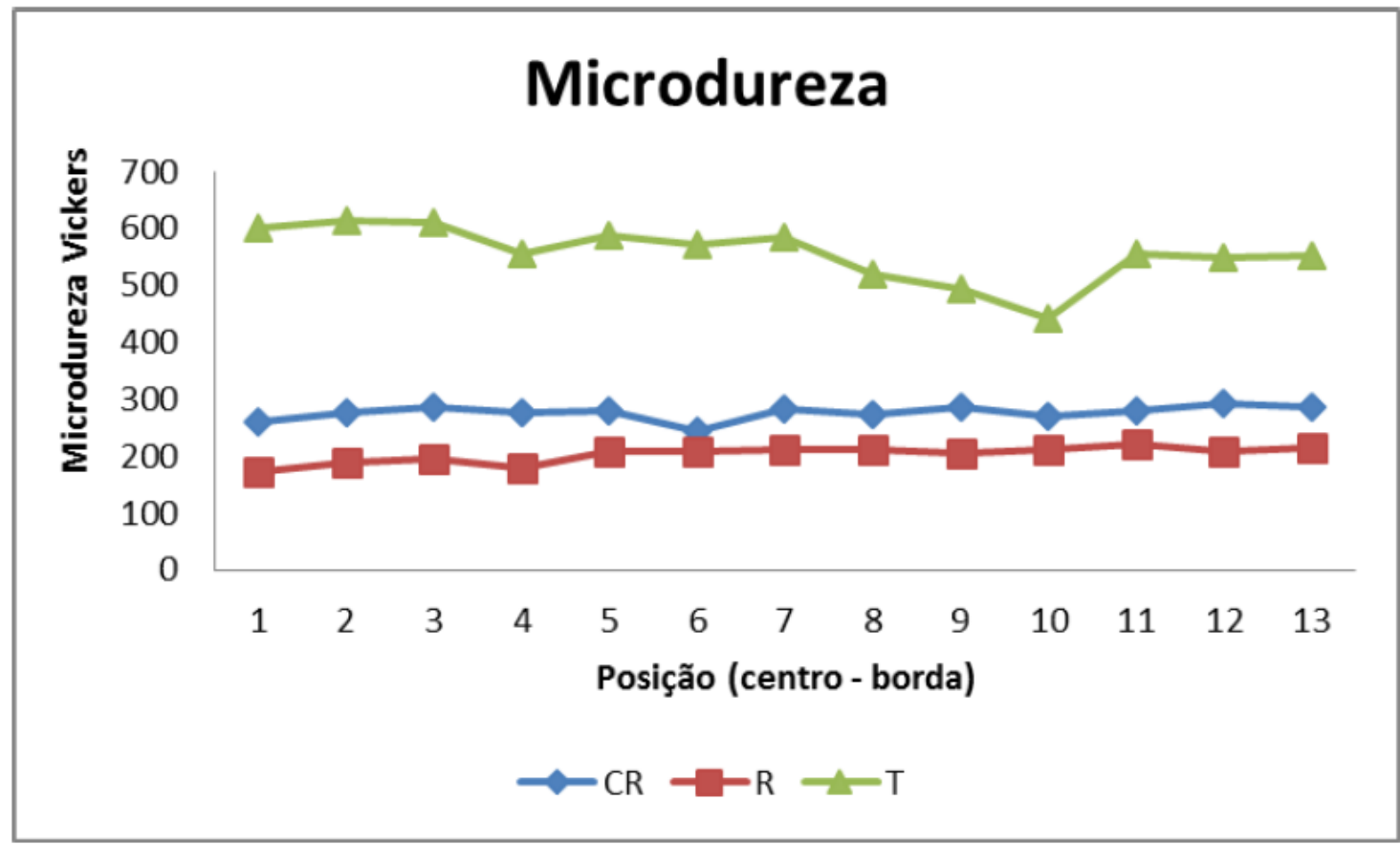

Figura 6. Gráfico de Microdureza Vickers para os três estados.

O estado como recebido apresentou dureza variando de 260 a 290HV (figura 6), observa-se que esses valores são pouco superiores aos do estado recozido. Isso pode ser explicado pelo tamanho dos grãos desses dois estados, pois grão menores resultam em durezas maiores, sendo o inverso verdadeiro. A dureza do estado recozido de 150 a $250 \mathrm{HV}$ já era esperada, visto que na literatura encontra-se que o aço 1040 recozido, o qual possui quantidade de carbono semelhante ao material utilizado, possui entre 137 e 207HB, convertendo para dureza Vickers tem-se 145 a $220 \mathrm{HV}$. Era esperado que a dureza da borda desses dois estados fosse maior que a dureza do centro, porém a dureza das bordas é apenas ligeiramente superior, indicando que a variação do tamanho de grão entre borda e centro não é tão significativa para esse parâmetro. Na temperada, além da dureza ter aumentado consideravelmente, quase o triplo do valor da como recebida, percebe-se variações nos valores bem maiores que os outros estados, podendo ser devido a irregularidades na formação da martensita ou irregularidades do próprio material. 


\subsection{Ensaio de tração}

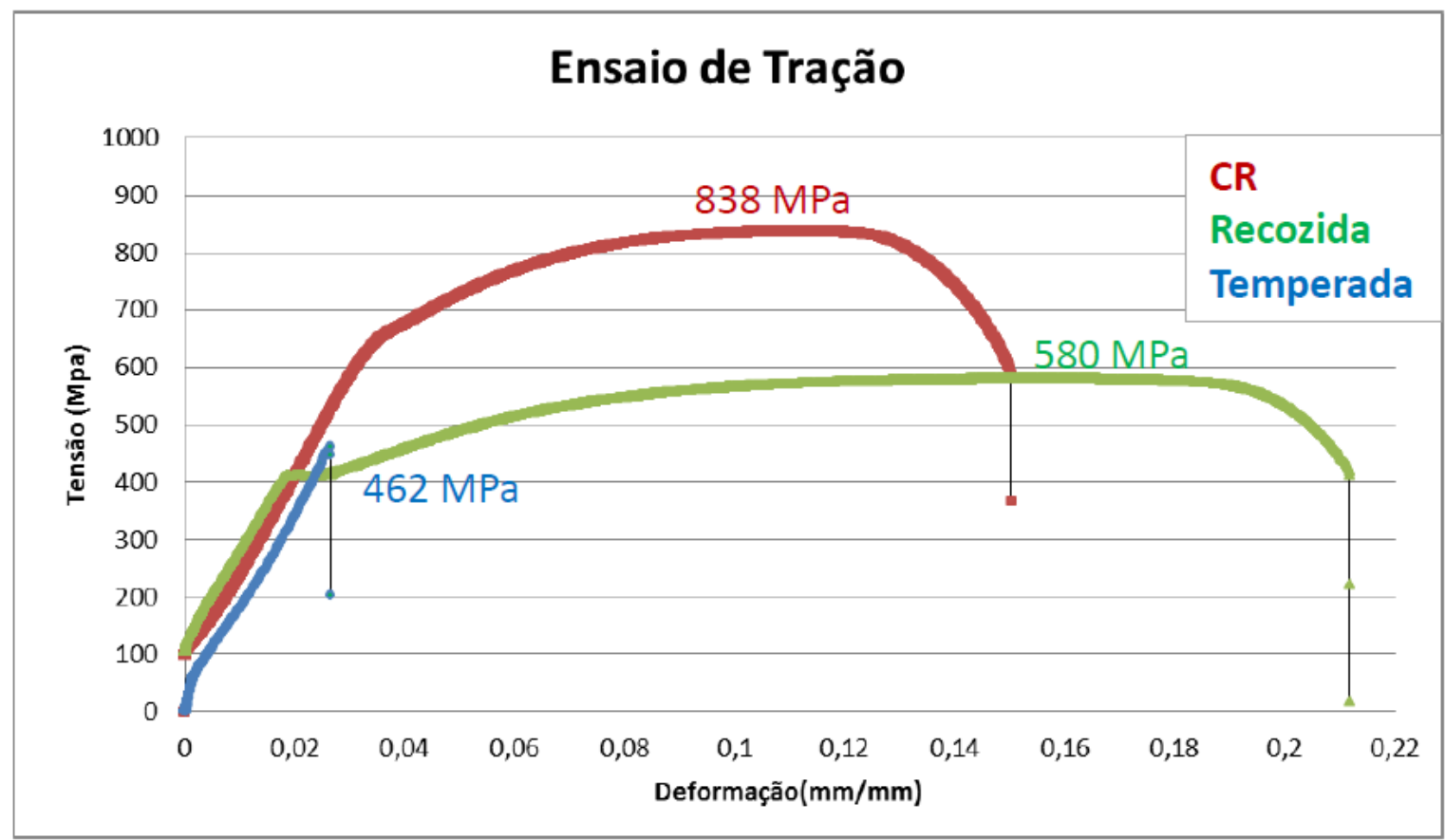

Figura 7. Gráfico Tensão x Deformação das amostras nos três estados.

A amostra como recebida apresentou resultados esperados (figura 7), com limite de escoamento por volta de 500 a $600 \mathrm{MPa}$, e além disso apresentou boa ductilidade e alongamento, porém encontrou-se valor de limite de resistência por volta de $800 \mathrm{MPa}$, sendo superior ao esperado. A literatura diz que o valor do limite de escoamento deve ser de $500 \mathrm{MPa}$ e que o alongamento deve ser de $8 \%$, mas o limite de resistência deve ser 1,08 vezes do valor do escoamento, sendo $540 \mathrm{MPa}$. Um dos motivos para este valor de limite de resistência ser maior que o da literatura, pode ser explicado pelo fato do corpo de prova ter sido ensaiado com tamanho diferente do produto testado normalmente, pois sabe-se que o tamanho e a geometria do corpo de prova podem influenciar na curva Tensão x Deformação do mesmo, visto que corpos de prova maiores possuem mais defeitos por probabilidade, podendo resistir menos que corpos de prova menores, como foi o caso desse trabalho (MARCHIORI, 1997, p. 68), porém o aumento é muito elevado para este ser o único mecanismo de aumento do limite de resistência, necessitando-se de maiores estudos para uma melhor conclusão deste fenômeno. O estado recozido apresentou aumento na ductilidade, porém menores valores de limite de escoamento ( 400 MPa), e limite de resistência ( 600 MPa), sendo inadequado para aplicação prática, pois o limite de escoamento é um requisito muito importante no mercado de vergalhões, visto que esses não podem deformar plasticamente, quando inseridos em uma estrutura, pois isso poderia levar ao colapso da construção.

O estado temperado apresentou ausência do fenômeno de estricção durante o ensaio. Isso é refletido no seu gráfico tensão $x$ deformação, o qual não apresenta a região de deformação plástica. Esse fenômeno ocorre devido ao grande aumento de dureza e, ao mesmo tempo, fragilização do material na presença de estrutura martensítica. Esse tipo de microestrutura também não é indicado para aplicação no mercado, pois qualquer sobrecarga levaria os vergalhões a romperem-se, levando ao desmoronamento das construções. 


\subsection{Tenacidade estimada}

Tabela 2 - Tenacidade calculada para os três estados

Amostra

Como recebida

Recozida

Temperada
Tenacidade (MJ/m3)

103,33

110,14

7,3

Os resultados da tenacidade são apresentados na tabela 2. A amostra recozida apresentou os maiores valores de tenacidade, causado pelo recozimento ao forno, que permitiu uma difusão facilitada do carbono na matriz, favorecendo a formação de uma microestrutura de perlita grosseira, o que contribuiu para a elevação da ductilidade e tenacidade do material em comparação com a condição como recebida. No caso da amostra temperada, o valor de tenacidade obtido foi muito baixo, confirmando assim a transição dúctil-frágil sofrida pelo material durante a têmpera. Espera-se que com o revenimento, a peça ganhe consideravelmente em tenacidade sem perder uma parcela significativa de dureza.

Para a amostra como recebida resultados apresentam boa resistência ao escoamento, ductilidade e tenacidade. Os materiais tratados termicamente apresentaram tenacidade intermediária entre as amostras recozida e temperada, tendendo muito mais para a recozida devido à elevada ductilidade requerida. Assim, os resultados se assemelham aos encontrados na literatura.

\subsection{Fractografias}
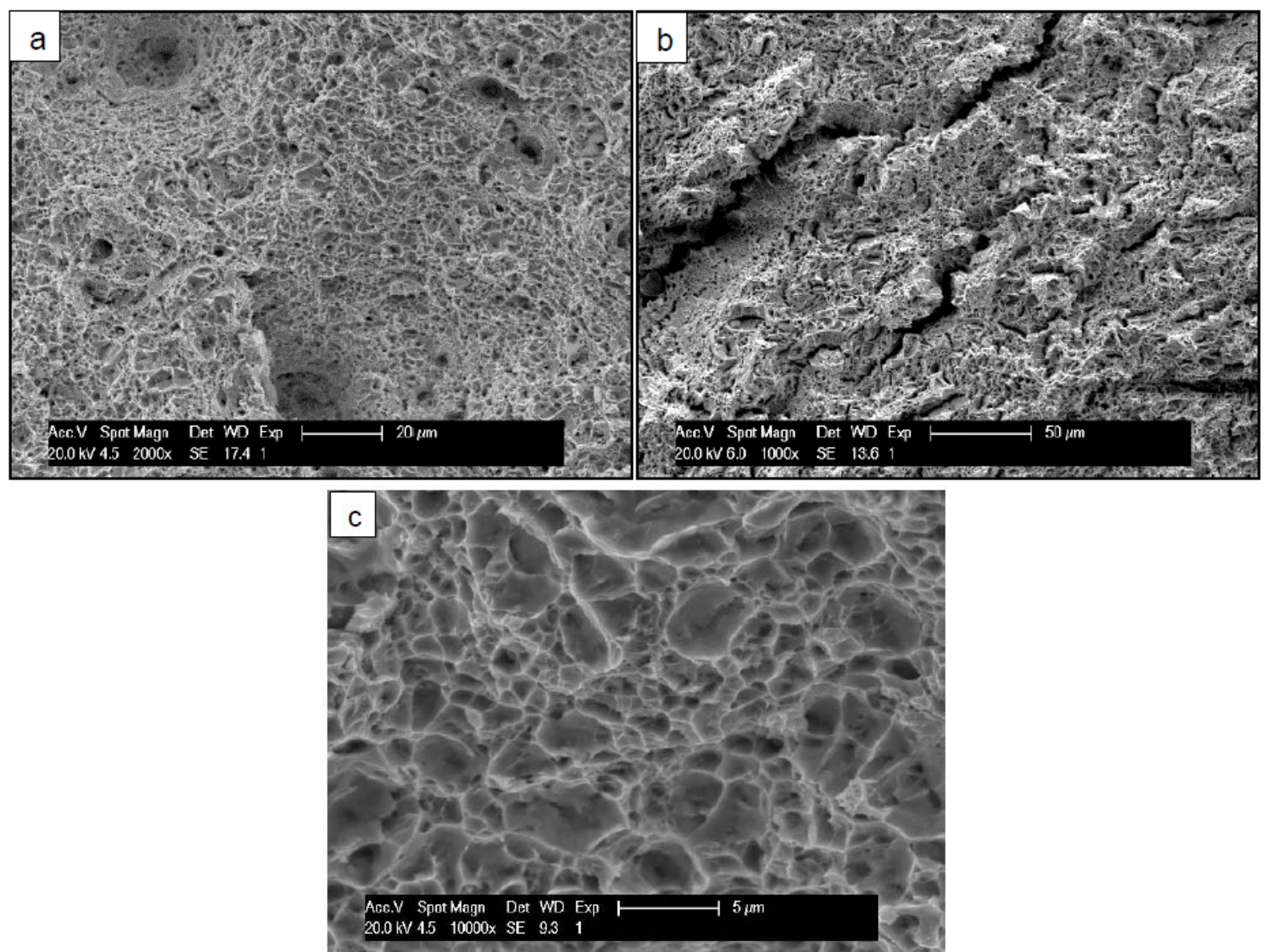

Figura 8. Micrografias eletrônicas da região fraturada da amostra como recebida com aumentos de a) 2000x, b) 1000x e c)10000x. 

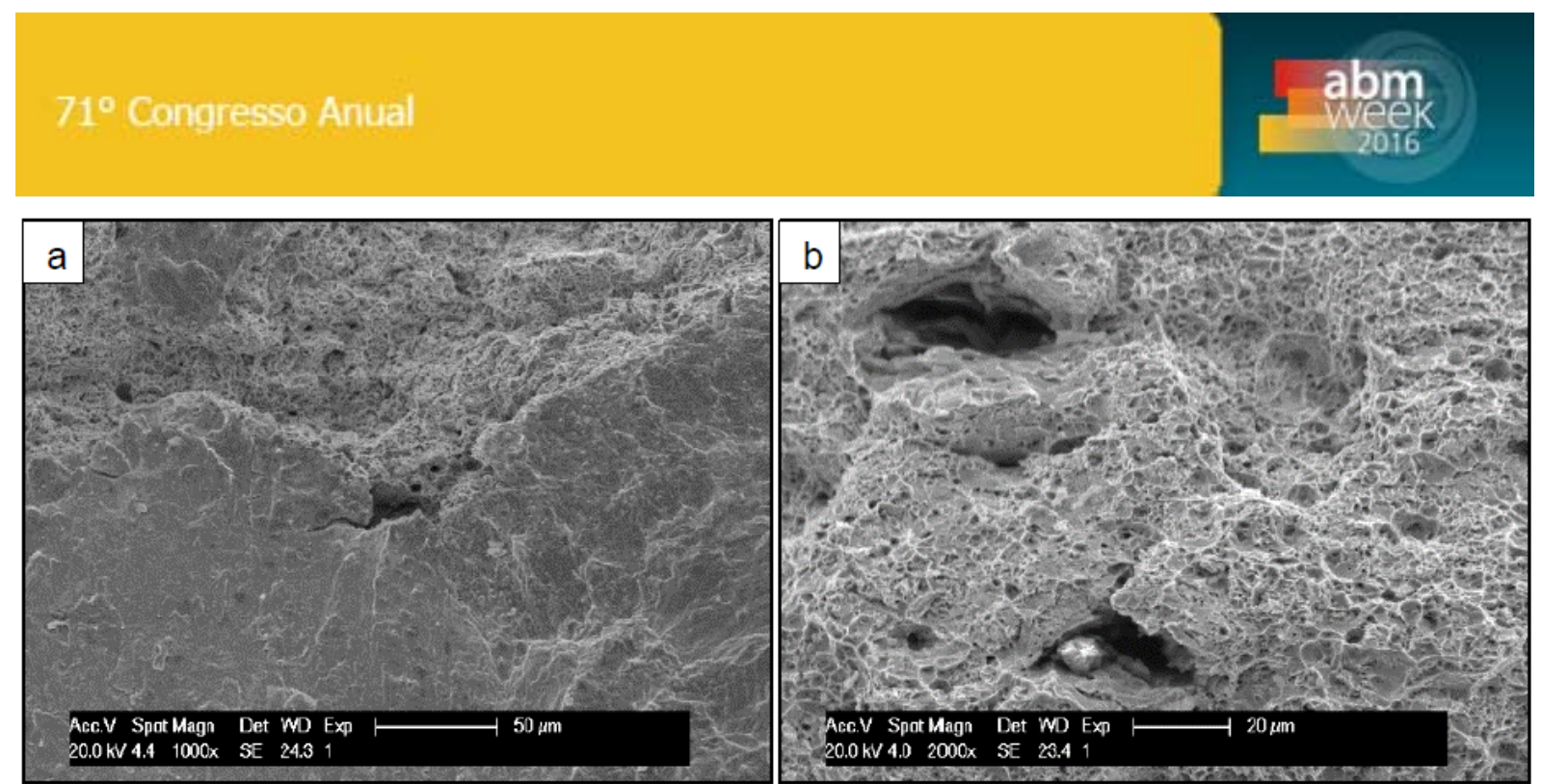

Figura 9. Micrografia eletrônica da região fraturada da amostra recozida em diferentes regiões a) centro e b) borda.
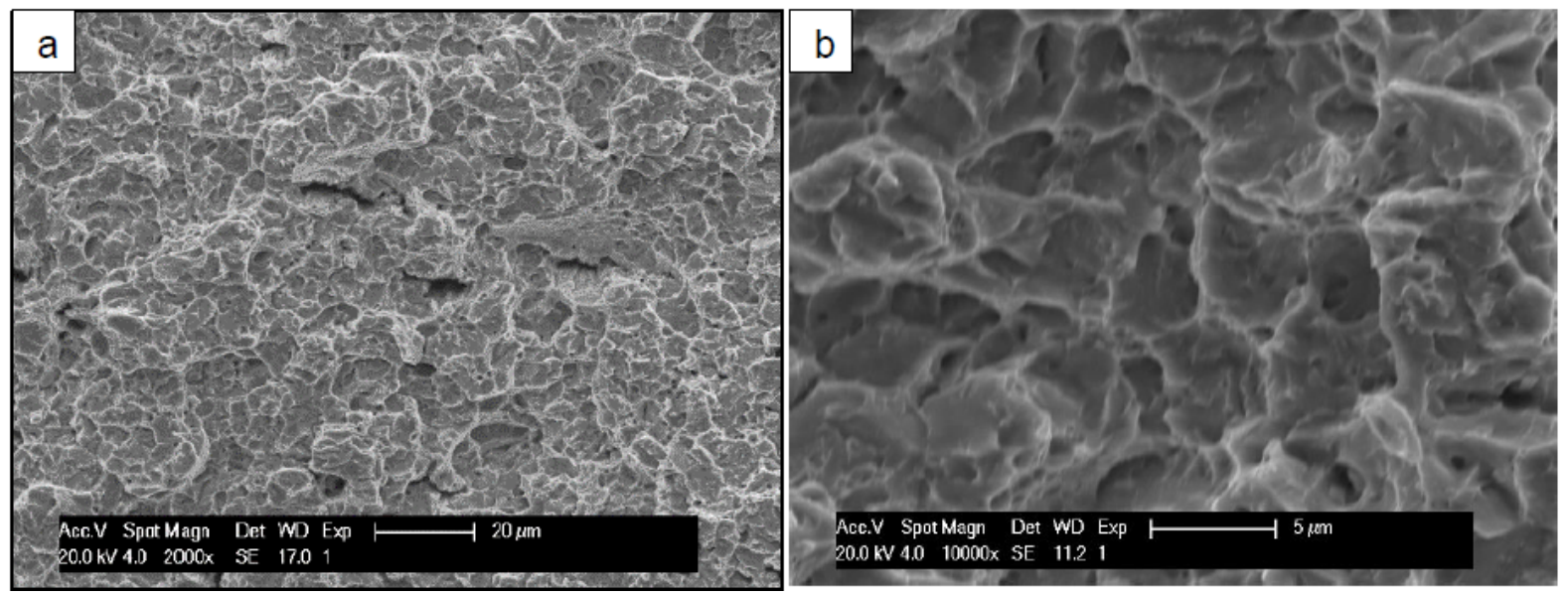

Figura 10 - Região fraturada da amostra temperada. a) 2000x e b) 10000x.

A amostra como recebida apresentou fratura característica de material dúctil, apresentando longas trincas na região da borda e região intermediária (figura 8b), e grandes e diversos dimples (figura 8 a e 8c), indicando grande deformação plástica antes da ruptura do material. O mesmo pode ser observado no estado recozido, grandes e diversos dimples (figura 9b), porém não apresenta trincas propagadas. Observa-se a presença de grandes cavidades abertas e deformadas, isso pode ser devido à grande plasticidade do material. No centro da fratura, a qual foi a última região a se desprender por completo, observa-se ausência de dimples e uma superfície que se assemelha a quase clivagem (figura 9a). Isso ocorre, pois essa região concentrou o encruamento causado no ensaio, diminuindo a ductilidade do material nesse ponto.

O estado temperado apresentou estrutura bem diferente dos outros dois, com ausência de dimples e de longas trincas (figura 10a). As trincas presentes podem ser classificadas como microtrincas, pois seu tamanho é diminuto. Percebe-se pouquíssima deformação, além de ser possível identificar o formato dos grãos da estrutura, indicando fratura intergranular (figura 10b). Além disso, a superfície da fratura apresentou-se homogênea e perpendicular ao comprimento do vergalhão. Essa fratura pode ser enquadrada como frágil. 


\section{CONCLUSÃO}

Foi possível constatar a grande influência na microestrutura e, consequentemente, nas propriedades mecânicas, provocadas pelos tratamentos térmicos, visto que foram obtidos microestruturas e propriedades diferentes entre os três estados de tratamentos.

O estado recozido apresentou maior ductilidade e tenacidade, porém menores valores de limite de escoamento e de resistência, não sendo indicado para aplicação comercial. O estado temperado apresentou menor ductilidade e tenacidade, porém apresenta o mais alto valor de dureza.

O vergalhão como recebido apresentou a melhor combinação entre todas as propriedades avaliadas para aplicação nas construções com concreto armado, sendo assim, os tratamentos de têmpera e recozimento não geraram propriedades adequadas para tais aplicações.

\section{Agradecimentos}

A Deus, pela força concedida nos momentos de dificuldade. Aos familiares, que torceram pela conclusão deste trabalho. Aos membros do Laboratório de Caracterização de Materiais. Ao professor Dr. Cleiton Carvalho Silva que nos forneceu a fundamentação teórica das técnicas de microscopia.

\section{REFERÊNCIAS}

1 DAROIT, Mateus. Estudo de aço microligado ao vanádio para a produção de barra nervurada para concreto armado com característica de soldabilidade segundo norma ABNT NBR 8965:1985. Dissertação (Mestrado em Engenharia) - Escola de

Engenharia, Universidade Federal do Rio Grande do Sul, Rio Grande do Sul. 2012.

2 R.M. Anazawa; A.J. Abdalla. Caracterização microestrutural e mecânica dos aços 4340 e 300M após tratamentos térmicos isotérmicos e intercríticos. VI Conferência Brasileira sobre Temas de Tratamento Térmico. Atibaia, SP, Brasil. 2012.

3 FERREIRA, Helder C. Efeito do bandeamento e taxa de resfriamento na ocorrência de austenita retida em aço baixo carbono com adições de manganês e silício. Tese de Doutorado - Programa de Pós-Graduação em Engenharia Metalúrgica, Materiais e de Minas da Universidade Federal de Minas Gerais. Belo Horizonte, 2015.

4 AMERICAN SOCIETY FOR TESTING AND MATERIALS. ASTM E 384: Standard Test Method for Microindentation Hardness of Materials. West Conshohocken, PA, 2008.

5 AMERICAN SOCIETY FOR TESTING AND MATERIALS. ASTM E8/E8M: Standard Test Methods for Tension Testing of Metallic Materials. West Conshohocken, PA. 2015.

6 PEREIRA, Raul. Ajuste da composição química do aço CA-50 em usina siderúrgica semi-integrada. Trabalho de Conclusão de Curso (Tecnólogo em Tecnologia em Processos Metalúrgicos) - Centro Universitário Estadual da Zona Oeste, Rio de Janeiro. 2009.

7 MARCHIORI, Daniela Gírio. Mecânica da fratura elástica linear e o modelo coesivo na previsão do faturamento de rochas. Dissertação - Universidade de São Paulo, São Carlos. 1997, p. 6-8. 